\title{
A study on religious values
}

\author{
Robabeh Poorjebelli, Mahboobeh Babaei and Mahsa Allahyari*
}

Department of Social Research, Faculty of Humanities and Social Sciences, Zanjan Branch, Islamic Azad University, Zanjan, Iran

\section{CHRONICLE ABSTRACT}

Article history:

Received February 252014

Accepted 17 July 2014

Available online

July 252014

Keywords:

Adherence to religious values

Ethnic Kurds

Turks

\begin{abstract}
This study aims to evaluate and to compare the adherence rate of religious values between the two ethnic groups of Turkish and Kurdish who live in West Azerbaijan province. The study designs a questionnaire in Likert scale, low, medium and high, and distributes it among a sample of 200 people who live in these two regions. The result of our survey indicates that Azeri people were more religious than Kurdish people were. In addition, the study investigates the relationship between personal characteristics including age, gender and marital status and adherence rate of religious values and detects some meaningful relationships between these two items.
\end{abstract}

\section{Introduction}

Ethical and religious believes normally helps people improve their life style and contribute more on society (Turner, 1991; Hogg et al., 2010). Religious people may be found more reliable for job opportunities since they could be trusted, more easily (Worthington, 1988). Jacobs (1984) stated that the economy of love in religious commitment. There are literally any studies on learning about ethical adherence in various societies. Roccas (2005), for instance, reviewed some studies on values and religiosity across cultural and religious groups. Rupasingha (2009) discussed religious adherence and county economic growth in the US. According to Sloan (1999), religion and science share a complex history as well as a complex present. At different times, the same person dispensed worldwide, medical and spiritual care. At other times, passionate conflicts characterized the association between religion and medicine and science. Kim (2007) discussed adherence to Asian and European American cultural values and attitudes toward looking professional psychological help among Asian American college students. She examined the characteristics of female religious commitment by concentrating on conversion to and disaffection from nontraditional religious movements. The seventeen subjects in the investigation represented a wide variety of religious orientations, ranging from charismatic Christianity to Eastern mysticism, with their commitment varying over time from six weeks to ten

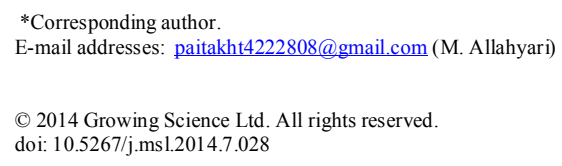


years. She reported that in religious commitment an economy of love was operationalized in which the commodities of exchange were affection, approval, and intimacy.

\section{The proposed study}

This study aims to evaluate and to compare the adherence rate of religious values between the two ethnic Azeri city of Falcon fort and Kurd Tekab in West Azerbaijan province. The sample size of the study has been calculated as follows,

$n=\frac{N \times z_{\alpha / 2}^{2} \times p \times q}{\varepsilon^{2} \times(N-1)+z_{\alpha / 2}^{2} \times p \times q}$,

where $N$ is the population size, $p=1-q$ represents the yes/no categories, $z_{\alpha / 2}$ is CDF of normal distribution and finally $\varepsilon$ is the error term. Since we have $p=0.5, z_{\alpha / 2}=1.96$ and $N=600$, the number of sample size is calculated as $n=200$.

The study designs a questionnaire in Likert scale, low, medium and high, and distributes it among a sample of 200 people, 100 men and 100 women, who live in these two regions. Fig. 1 demonstrates some other personal characteristics of the participants, which includes their age and marital status.

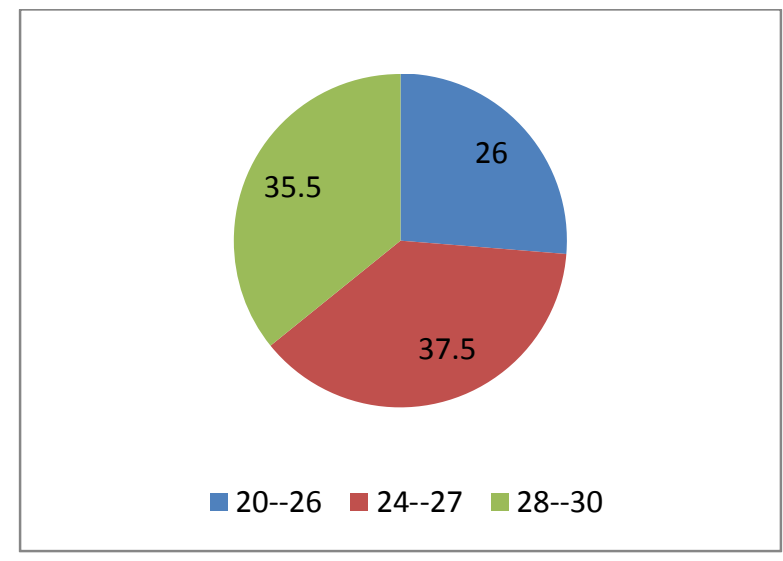

Age

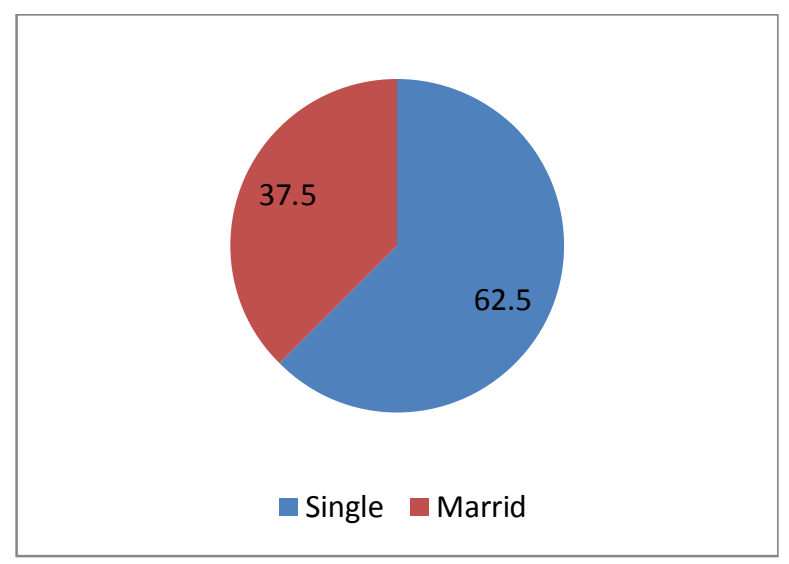

Marital status

Fig. 1. Personal characteristics of the participants

As we can observe from the results of Fig. 1, most participants were single and middle aged people. In addition, we have surveyed the level of education of the people and their parents who took part in our survey. Fig. 2 shows details of our survey.

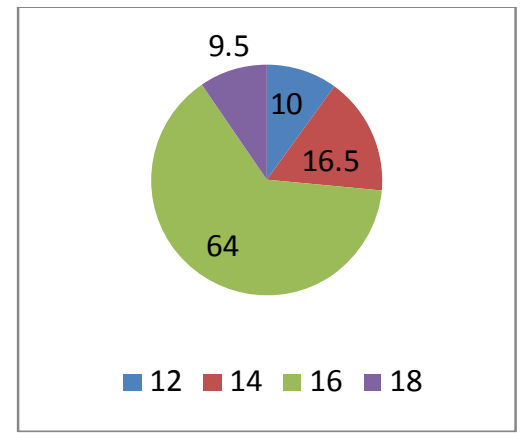

Participants

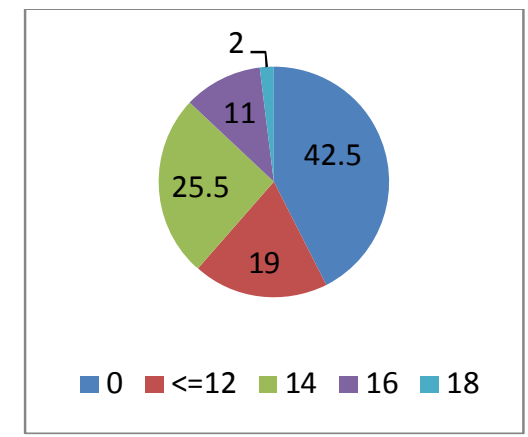

Participants' father

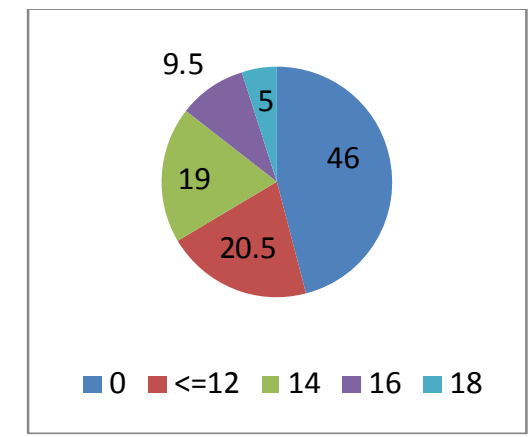

Participants' mother

Fig. 2. Participants' educational background in terms of years of education 
According to Fig. 2, most participants maintained good educational backgrounds but their parents did not have any good educational backgrounds. Next, we present the level of religious believes among Turkish and Kurdish ethnic groups in Fig. 3 as follows,

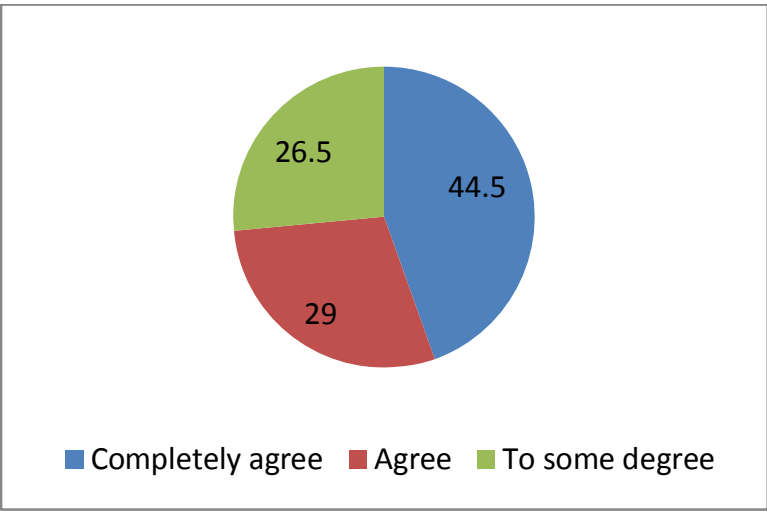

Azari people

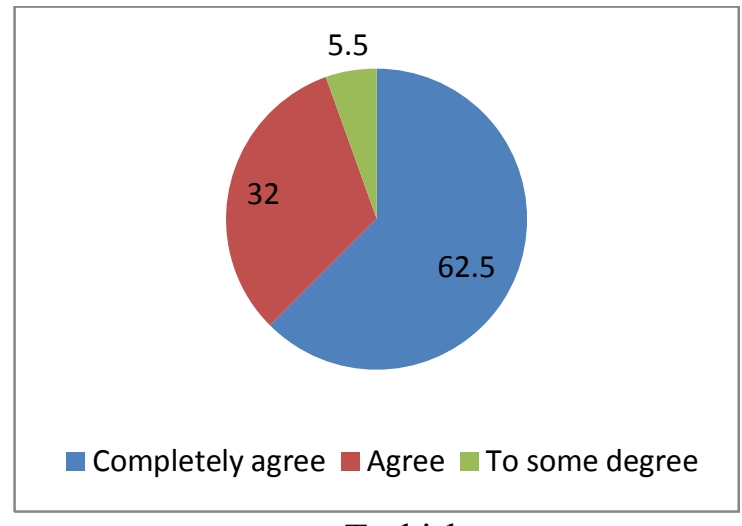

Turkish

Fig. 3. The level of Religious believes

According to the results of Fig. 3, Turkish people tend to adhere to religious believes more than Azari people. The proposed study considers six hypotheses as follows,

1. There is a meaningful relationship between adherence to religious values and gender.

2. There is a meaningful relationship between adherence to religious values and marital status.

3. There is a meaningful relationship between adherence to religious values and educational backgrounds.

4. There is a meaningful relationship between adherence to religious values and age.

5. There is a meaningful difference between adherence to religious values in two Turkish and Kurdish tribes.

6. There is a meaningful difference between adherence/not adherence to religious values in two Turkish and Kurdish tribes.

Table 1 demonstrates the results of Cronbach alpha for six hypotheses of this survey.

\section{Table 1}

The summary of Cronbach alpha

\begin{tabular}{lcccccc}
\hline Hypothesis & 1 & 2 & 3 & 4 & 5 & 6 \\
\hline \# of questions & 9 & 8 & 7 & 7 & 7 & 5 \\
Cronbach alpha & 0.73 & 0.81 & 0.89 & 0.85 & 0.86 & 0.79 \\
\hline
\end{tabular}

As we can observe from the results of Table 1, all Cronbach alphas are well above the minimum acceptable level of 0.70. In addition, Kolmogorov-Smirnov test has indicated that all data were normally distributed.

\section{The results}

In this section, we present details of our results on testing six hypotheses of the survey.

\subsection{The first hypothesis: The relationship between religious values and gender}

The first hypothesis of this survey investigates the relationship between religious values and gender. Table 2 shows details of the implementation of t-student test between two groups of men and women. 
Table 2

The summary of testing the relationship between religious values and gender

\begin{tabular}{cccccccccc}
\hline & \multicolumn{2}{c}{ Leven's test } & \multicolumn{5}{c}{ t-test for equality of means } \\
\cline { 2 - 10 } & $\mathrm{F}$ & Sig. & t-value & df & Sig. (2-tailed) & Mean diff. & Std. Error & Lower & Upper \\
\hline$\sigma_{1}^{2}=\sigma_{2}^{2}$ & 17.606 & 0.000 & -21.671 & 198 & 0.000 & -72.09 & 3.32655 & -72.29 & -71.88 \\
$\sigma_{1}^{2} \neq \sigma_{2}^{2}$ & & & -21.671 & 174.434 & 0.000 & -72.09 & 3.32655 & -72.29 & -71.88 \\
\hline
\end{tabular}

As we can observe from the results of Table 2, the null hypothesis for equality of variances is rejected leaving us to use the information of the second row, which implies that there was a meaningful difference between the mean of gender and adherence to religion. Table 3 presents the results of mean and standard deviation of the information.

Table 3

The summary of mean and standard deviation

\begin{tabular}{lcccc}
\hline Gender & $\mathrm{N}$ & Mean & Standard deviation & Standard error \\
\hline Men & 100 & 1.6400 & 18.70 & 1.87 \\
Women & 100 & 1.7300 & 27.50 & 2.70 \\
\hline
\end{tabular}

Based on the results of Table 3, we can conclude that women were more religious than men were.

\subsection{The second hypothesis: The relationship between religious values and marital status}

The second hypothesis of this survey studies the relationship between religious values and marital status. Table 4 demonstrates details of the implementation of t-student test between two groups of single and married.

\section{Table 4}

The summary of testing the relationship between religious values and marital status

\begin{tabular}{cccccccccc}
\hline & \multicolumn{7}{c}{ Leven's test } & \multicolumn{7}{c}{ t-test for equality of means } \\
\cline { 2 - 10 } & $\mathrm{F}$ & Sig. & t-value & $\mathrm{df}$ & Sig. (2-tailed) & Mean diff. & Std. Error & Lower & Upper \\
\hline$\sigma_{1}^{2}=\sigma_{2}^{2}$ & 0.000 & 0.005 & 3.895 & 198 & 0.000 & -74.68 & 3.41 & -74.89 & -74.46 \\
$\sigma_{1}^{2} \neq \sigma_{2}^{2}$ & & & 3.907 & 156.215 & 0.000 & -74.68 & 3.40 & -74.89 & -74.46 \\
\hline
\end{tabular}

As we can observe from the results of Table 4, the null hypothesis for equality of variances is accepted leaving us to use the information of the first row. Table 5 shows the results of mean and standard deviation of two groups.

\section{Table 5}

The summary of mean and standard deviation

\begin{tabular}{lcccc}
\hline Gender & $\mathrm{N}$ & Mean & Standard deviation & Standard error \\
\hline Single & 125 & 1.6800 & 23.37 & 2.09 \\
Married & 75 & 1.3600 & 23.32 & 2.69 \\
\hline
\end{tabular}

Based on the results of Table 3, we can conclude that singles were more religious than married were.

\subsection{The third hypothesis: The relationship between religious values and educational background}

The third hypothesis of this survey tries to find out the relationship between religious values and educational background. Table 6 presents details of the implementation of ANOVA test between two groups. 
Table 6

The summary of ANOVA test

\begin{tabular}{lccccc}
\hline & Sum of squares & df & Mean Squares & F & Sig. \\
\hline Between groups & 272270.2 & 3 & 0.726 & 1.137 & 0.000 \\
Within groups & 97130.977 & 196 & 0.566 & & \\
\hline Total & 369401.2 & 199 & & & \\
\hline
\end{tabular}

As we can observe from the results of Table 6, the null hypothesis for equality of variances is rejected and we can conclude that education plays an important role on influencing religious adherence and we can confirm the third hypothesis.

\subsection{The fourth hypothesis: The relationship between religious values and participants' age}

The fourth hypothesis of this survey tries to look at the relationship between religious values and participants' age. Table 7 gives us details of the implementation of ANOVA test between two groups.

Table 7

The summary of ANOVA test

\begin{tabular}{lccccc}
\hline & Sum of squares & df & Mean Squares & F & Sig. \\
\hline Between groups & 57184.835 & 2 & 28592.418 & 6.041 & 0.000 \\
Within groups & 3122163 & 197 & 1584.854 & & \\
\hline Total & 369401.2 & 199 & & & \\
\hline
\end{tabular}

As we can observe from the results of Table 7, the null hypothesis for equality of variances is rejected and we can conclude that age plays an essential role on influencing religious adherence and we can confirm the fourth hypothesis. In order to find out which groups of participants are more religious we have performed Dunnett test and Table 8 shows the results of our survey.

Table 8

The summary of Dunnett test

\begin{tabular}{|c|c|c|c|c|c|}
\hline \multirow[b]{2}{*}{ Age (I) } & \multirow[b]{2}{*}{$\operatorname{Age}(J)$} & \multicolumn{2}{|l|}{ Mean difference } & \multicolumn{2}{|c|}{ 95\% Confidence Interval } \\
\hline & & $(\mathrm{I}-\mathrm{J})$ & Std. Error & Lower bound & Upper bound \\
\hline \multirow[b]{2}{*}{$20-23$} & $24-27$ & -9.52231 & 8.09196 & -28.9924 & 9.9477 \\
\hline & $28-30$ & -39.880066 & 7.47033 & -57.8760 & -21.8853 \\
\hline \multirow{2}{*}{$24-27$} & $20-23$ & 9.52231 & 8.09196 & -9.9477 & 28.9924 \\
\hline & $28-30$ & -30.35836 & 6.06500 & -44.8675 & -15.8493 \\
\hline \multirow[b]{2}{*}{$28-30$} & $20-23$ & 39.88066 & 7.47033 & 21.8853 & 57.8760 \\
\hline & $24-27$ & 30.35836 & 6.06500 & 15.8493 & 44.8675 \\
\hline
\end{tabular}

Based on the information of Table 8, as people get older, they tend to become more religious.

\subsection{The fifth hypothesis: The relationship between religious values of two groups}

The fifth hypothesis of this survey investigates the relationship between religious values of two Turkish and Kurdish groups. Table 8 presents details of the implementation of ANOVA test between two groups.

\section{Table 8}

The summary of ANOVA test

\begin{tabular}{lccccc}
\hline & Sum of squares & df & Mean Squares & F & Sig. \\
\hline Between groups & 6.038 & 3 & 2.013 & 5.015 & 0.002 \\
Within groups & 152.098 & 196 & 0.401 & & \\
\hline Total & 158.136 & 199 & & & \\
\hline
\end{tabular}


As we can observe from the results of Table 8, the null hypothesis for equality of variances is rejected and we can conclude that there is a difference between adherences to religion in two groups. In fact, Turkish ethnic group tends to be more religious than Kurdish people do.

3.6. The sixth hypothesis: The relationship between adherence/not adherence to religious values in two Turkish and Kurdish tribes

The last hypothesis of this survey investigates the relationship between adherence/not adherence to religious values in two Turkish and Kurdish tribes. Table 9 presents details of the implementation of ANOVA test between two groups.

\section{Table 9}

The summary of ANOVA test

\begin{tabular}{lccccc}
\hline & Sum of squares & df & Mean Squares & F & Sig. \\
\hline Between groups & 9.059 & 3 & 3.020 & 5.913 & 0.001 \\
Within groups & 193.542 & 196 & 0.511 & & \\
\hline Total & 202.601 & 199 & & & \\
\hline
\end{tabular}

As we can observe from the results of Table 9, the null hypothesis for equality of variances is rejected and we can conclude that there is a difference between adherence/not adherence to religious values in two Turkish and Kurdish tribes.

\section{Conclusion}

In this paper, we have presented an empirical investigation to study the level of religious believes among two groups of Turkish and Kurdish tribes in province of Azarbaeejan, Iran. The results of our survey have indicated while women were more religious than men were, single people seemed to be more religious than married ones. In addition, the study has indicated that as people get older, they tend to become more religious and finally, Turkish people seemed to be more religious than Kurdish people did.

\section{References}

Hogg, M. A., Adelman, J. R., \& Blagg, R. D. (2010). Religion in the face of uncertainty: An uncertainty-identity theory account of religiousness. Personality and Social Psychology Review, 14(1), 72-83.

Jacobs, J. (1984). The economy of love in religious commitment: The deconversion of women from nontraditional religious movements. Journal for the Scientific Study of Religion, 58(2), 155-171.

Kim, B. S. (2007). Adherence to Asian and European American cultural values and attitudes toward seeking professional psychological help among Asian American college students. Journal of Counseling Psychology, 54(4), 474.

Roccas, S. (2005). Religion and value systems. Journal of Social Issues, 61(4), 747-759.

Rupasingha, A. (2009). Religious adherence and county economic growth in the US. Journal of Economic Behavior \& Organization, 72(1), 438-450.

Sloan, R. P., Bagiella, E., \& Powell, T. (1999). Religion, spirituality, and medicine. The Lancet, 353(9153), 664-667.

Turner, B. S. (1991). Religion and social theory (Vol. 10). Sage.

Worthington, E. L. (1988). Understanding the values of religious clients: A model and its application to counseling. Journal of Counseling Psychology,35(2), 166. 